OPEN ACCESS

Edited by:

Slobodan Paessler

The University of Texas Medical

Branch at Galveston, United States

Reviewed by:

Brian Carey,

United States Army Medical Research Institute of Infectious Diseases

(USAMRIID), United States

Sabrina John Moyo,

University of Bergen, Norway

Robert Cody Sharp,

University of Florida Health

United States

${ }^{*}$ Correspondence

Yanli Yang

yangyanli0702@126.com

Specialty section

This article was submitted to

Clinical Microbiology,

a section of the journal

Frontiers in Cellular and Infection

Microbiology

Received: 03 April 2020

Accepted: 25 August 2020

Published: 15 September 2020

Citation:

Li D, Liu C, Liu J, Hu J, Yang Y and Zhou Y (2020) Analysis of Risk Factors for 24 Patients With COVID-19

Developing From Moderate to

Severe Condition.

Front. Cell. Infect. Microbiol. 10:548582.

doi: $10.3389 /$ fcimb.2020.548582

\section{Analysis of Risk Factors for 24 Patients With COVID-19 Developing From Moderate to Severe Condition}

\author{
Dianming $\mathrm{Li}^{1}$, Chuanmiao $\mathrm{Liu}^{2}$, Jiahui Liu ${ }^{1}$, Junfeng $\mathrm{Hu}^{1}$, Yanli Yang ${ }^{3 *}$ and Yufu Zhou ${ }^{4}$ \\ ${ }^{1}$ Department of Respiratory and Critical Care Medicine, The First Affiliated Hospital of Bengbu Medical College, Bengbu, \\ China, ${ }^{2}$ Department of Infectious Diseases, The First Affiliated Hospital of Bengbu Medical College, Bengbu, China, \\ ${ }^{3}$ Department of Hematology, The First Affiliated Hospital of Bengbu Medical College, Bengbu, China, ${ }^{4}$ Department of Tumor \\ Radiotherapy, The First Affiliated Hospital of Bengbu Medical College, Bengbu, China
}

Objective: The present study aimed at investigating the clinical risk factors for COVID-19 patients developing from moderate condition to severe condition, and providing reference for early intervention and prognosis.

Methods: We collected the clinical data of 24 patients with moderate-to-severe COVID-19 who were admitted to the isolation ward of the First Affiliated Hospital of Bengbu Medical College from January, 2020 to February 20, 2020, and evaluated the data of clinical characteristics, blood test results, inflammatory index, chest CT imaging characteristics, and antiviral treatment, comparing this with the clinical data of 41 patients with moderate condition in the same period. From this comparison we thus summarized the current knowledge of potential risk factors for COVID-19 patients developing from moderate to severe condition.

Results: (1) Clinical characteristics: The moderate-to-severe group and the moderate group in terms of combined common underlying diseases and respiratory frequency showed significant difference statistically ( $t$-value were 13.32, 6.17, respectively, $P<0.05)$, while no significant difference between the two groups in gender, age, or clinical symptoms was statistically observed( $P>0.05)$.

(2) Analysis of blood test results: The lymphocyte count and plasma albumin of the moderate-to-severe group were significantly lower than those of the moderate group ( $t$-values were 4.16, 4.11, respectively, $P<0.05$ ), and the blood glucose and urea of the moderate-to-severe group were significantly higher than those of the moderate group ( $t$-value were $3.27,4.19$, respectively, $P<0.05$ ). However, there was no significant difference in terms of white blood cell count (WBC), platelet count (PLT), and glutamic-pyruvic transaminase (GPT) $(P>0.05)$.

(3) Comparison of inflammatory indicators: The level of $\mathrm{IL}-6$ and CRP of the moderate-to-severe group were significantly higher than those of the moderate group ( $t$-values were 2.84, 4.88, respectively, $P<0.05$ ).

(4) Imaging comparison: As for patients with moderate COVID-19, the imaging manifestations were the concurrence of ground-glass opacity, patchy shadow, and consolidation shadow in both lungs, diffuse ground-glass opacity in both lungs accompanied by air bronchogram, and large area consolidation of both lungs with 
pulmonary interstitial changes. The possibility for these patients to develop into severe condition increased, and the differences were statistically significant $(t=10.92, P<0.05)$.

(5) Clinical antiviral treatment: There was no statistically significant difference in the combination of two or three antiviral drugs between the two groups $\left(\chi^{2}=0.05, P>0.05\right)$.

Conclusion: Current evidence suggested that the combination of common underlying diseases, respiratory frequency, lymphocyte count, blood glucose, albumin, urea level, inflammatory factors (CRP, IL-6), and imaging manifestations collectively contributed to the potential risk factors for the development of COVID-19 from moderate condition to severe condition. Particular attention should be paid to early detection and intervention during clinical work, which will be of vital significance to the ascent of the recovery rate as well as the reduction of mortality.

Keywords: COVID-19, moderate, severe, risk factors, IL-6

\section{INTRODUCTION}

Since December 2019, patients with novel coronavirus pneumonia have been detected in the city of Wuhan in Hubei province. With the rapid spread of the epidemic, additional cases have been found in other parts of China and abroad. The disease was officially named "2019 coronavirus disease" (COVID-19) by the Director-General of WHO, Tan Desai, on February 11th and a subsequent announcement by the National Center for Disease Control and Prevention declared the inclusion of COVID-19 in the national "class B" infectious diseases and the adoption of "class A" infectious disease prevention and control measures Novel coronavirus pneumonia diagnosis and treatment plan of People's Republic of China national health and Health Committee. Fundamental clinical and epidemiological studies on COVID-19 have been reported recently (Chan J. et al., 2020; Chen L. et al., 2020; Huang et al., 2020; Ren et al., 2020; Wang et al., 2020). With the efforts of positive and effective prevention and control measures throughout the country and the devotion from the vast majority of medical workers, the epidemic has been basically controlled. However, the number of cases has continued to grow dramatically among overseas countries, especially Italy, Spain, and others, accompanied by a relative high mortality rate. We found that some moderate patients tend to develop into severe condition in a short period of time, or even become critical, so it is very difficult to improve the level of treatment. The distinction for these patients in the early stage will be of great value to the improvement of diagnosis and treatment. In the study, we collected clinical data derived from 24 patients admitted to our hospital with COVID-19 developing from moderate to severe condition, compared this with the clinical data of 41 patients with moderate condition in the same period, and analyzed the potential risk factors for COVID-19 patients developing from moderate to severe condition.

\section{PATIENTS AND METHODS}

\section{Patients}

The study has been approved by the medical ethics committee of the First Affiliated Hospital of Bengbu Medical College, which conforms to the principles of the Declaration of Helsinki. Our hospital is the designated hospital for COVID-19 in Anhui Province, and one of the four intensive treatment bases for severe patients in the province. All the cases meet the COVID-19 diagnostic criteria (sixth edition): (1) epidemiological history: travel history or residential history in Wuhan and its surrounding areas or other communities with reported cases within 14 days before onset; history of contact with a novel coronavirus infected person (positive in nucleic acid test) within 14 days before onset; exposure to patients with fever or respiratory symptoms from Wuhan and its surrounding areas or other communities with reported cases within 14 days before onset; and a clustering onset of disease. (2) Clinical manifestations: fever and/or respiratory symptoms; the aforementioned imaging characteristics of COVID-19; and the total WBC is normal or decreased in the early stage, or the lymphocyte count is decreased. A suspected case can be diagnosed if the patient has any one of the characteristics of epidemiological histories and conforms to any two of the clinical manifestations. If the patient has no epidemiological history and conforms to three of the clinical manifestations, it can be diagnosed as a suspected case. The inclusion criteria for confirmed cases was: suspected cases with one of the following pieces of etiological evidence: positive nucleic acid of novel coronavirus was detected in Real-time fluorescence RT-PCR; or gene sequencing of the virus revealed a high homology with the novel coronavirus. We collected the clinical data of 24 patients with moderate-tosevere COVID-19 who were admitted to the isolation ward of the First Affiliated Hospital of Bengbu Medical College from January, 2020 to February 20, 2020, and evaluated the clinical characteristics, blood test results, inflammatory index, chest CT imaging characteristics, and antiviral treatment, comparing these with the clinical data of 41 patients with moderate condition in the same period, and summarized the potential risk factors for COVID-19 patients developing from moderate to severe condition.

\section{Clinical Typing of Disease Severity}

All confirmed patients were clinically classified according to the "diagnosis and treatment plan of novel coronavirus pneumonia" 
TABLE 1 | Comparison of clinical characteristics between two groups.

\begin{tabular}{|c|c|c|c|c|c|}
\hline \multicolumn{2}{|c|}{$\begin{array}{c}\text { General } \\
\text { information }\end{array}$} & \multirow{2}{*}{$\begin{array}{c}\text { Moderate- } \\
\text { to-severe } \\
\text { Group } \\
\text { (N=24) } \\
15\end{array}$} & \multirow{2}{*}{$\begin{array}{c}\text { Moderate } \\
\text { Group } \\
(\mathbf{N = 4 1 )} \\
20\end{array}$} & \multirow{2}{*}{$\begin{array}{l}\chi^{2} / t \\
\\
\\
1.15\end{array}$} & \multirow{2}{*}{$\begin{array}{r}\boldsymbol{P} \text {-value } \\
>0.05\end{array}$} \\
\hline Gender & Male & & & & \\
\hline & Female & 9 & 21 & & \\
\hline \multirow[t]{4}{*}{ Age } & $<40 \mathrm{yr}$ & 1 & 5 & 2.52 & $>0.05$ \\
\hline & $40-50 \mathrm{yr}$ & 4 & 11 & & \\
\hline & $51-60 \mathrm{yr}$ & 12 & 15 & & \\
\hline & $\geq 60 \mathrm{yr}$ & 7 & 10 & & \\
\hline \multirow{2}{*}{$\begin{array}{l}\text { Combined underlying } \\
\text { diseases }\end{array}$} & 1 & 13 & 36 & 13.32 & $<0.05$ \\
\hline & $\geq 2$ & 11 & 5 & & \\
\hline \multirow[t]{4}{*}{ Clinical symptoms } & Fever & 21 & 41 & 3.41 & $>0.05$ \\
\hline & Cough/sputum & 8 & 12 & & \\
\hline & $\begin{array}{l}\text { chest distress } \\
\text { and dyspnea }\end{array}$ & 3 & 1 & & \\
\hline & others & 0 & 1 & & \\
\hline \multirow[t]{2}{*}{ Main physical signs } & $<24$ times /min & 16 & 36 & 6.13 & $<0.05$ \\
\hline & $\geq 24$ times $/ \mathrm{min}$ & 8 & 5 & & \\
\hline
\end{tabular}

TABLE 2 | Comparison of hematological indexes between the two groups.

\begin{tabular}{lcccc}
\hline $\begin{array}{l}\text { Hematological } \\
\text { index }\end{array}$ & $\begin{array}{c}\text { Moderate-to-severe } \\
\text { Group }(\mathbf{N}=\mathbf{2 4})\end{array}$ & $\begin{array}{c}\text { Moderate Group } \\
(\mathbf{N}=\mathbf{4 1})\end{array}$ & $\boldsymbol{t}$ & $\boldsymbol{P}$-value \\
\hline WBC $\left(\times 10^{9} / \mathrm{L}\right)$ & $6.34 \pm 3.68$ & $6.42 \pm 3.53$ & 0.09 & $>0.05$ \\
$\begin{array}{l}\text { Lymphocyte } \\
\text { count }\left(\times 10^{9} / \mathrm{L}\right)\end{array}$ & $0.98 \pm 0.53$ & $1.56 \pm 0.55$ & 4.16 & $<0.05$ \\
PLT $\left(\times 10^{9} / \mathrm{L}\right)$ & $237.58 \pm 125.53$ & $257.68 \pm 84.12$ & 0.77 & $>0.05$ \\
Plasma allbumin & $35.03 \pm 5.92$ & $40.01 \pm 3.85$ & 4.11 & $<0.05$ \\
$\begin{array}{l}\text { (g/L) } \\
\text { ALT (U/L) }\end{array}$ & $42.88 \pm 41.83$ & $36.73 \pm 34.71$ & 0.63 & $>0.05$ \\
$\begin{array}{l}\text { Blood glucose } \\
\text { (mmo/L) }\end{array}$ & $8.84 \pm 3.88$ & $6.51 \pm 1.86$ & 3.27 & $<0.05$ \\
Urea (umol/L) & $5.97 \pm 2.96$ & $3.74 \pm 1.31$ & 4.19 & $<0.05$
\end{tabular}

TABLE 3 | Comparison of inflammatory indicators between the two groups.

\begin{tabular}{lcccc}
\hline $\begin{array}{l}\text { Inflammatory } \\
\text { indicators }\end{array}$ & $\begin{array}{c}\text { Moderate-to-severe } \\
\text { Group }(\mathbf{N}=\mathbf{2 4})\end{array}$ & $\begin{array}{c}\text { Moderate Group } \\
\mathbf{( N = 4 1 )}\end{array}$ & $\boldsymbol{t}$ & $\boldsymbol{P}$-value \\
\hline $\mathrm{IL}-6(\mathrm{pg} / \mathrm{ml})$ & $9.88 \pm 4.59$ & $6.69 \pm 4.23$ & 2.84 & $<0.01$ \\
$\mathrm{CRP}(\mathrm{mg} / \mathrm{L})$ & $47.88 \pm 16.63$ & $28.35 \pm 14.91$ & 4.88 & $<0.01$
\end{tabular}

at admission. Moderate condition was classified as a patient with fever and respiratory symptoms with whom manifestations of pneumonia can be found in imaging findings. Severe condition was classified based on any of the following: respiratory distress, $\mathrm{RR} \geq 30$ times/min; under resting state, oxygen saturation $\leq 93 \%$; and arterial partial oxygen pressure $\left(\mathrm{PaO}_{2}\right)$ /oxygen concentration $\left(\mathrm{FiO}_{2}\right) \leq 300 \mathrm{mmHg}(1 \mathrm{mmHg}=0.133 \mathrm{kpa})$.
Patients with lesion progression more than $50 \%$ shown by pulmonary imaging within $24-48$ h were managed under severe care Novel coronavirus pneumonia diagnosis and treatment plan of People's Republic of China national health and Health Committee.

\section{Test Method}

In the morning of the second day after admission, $2 \mathrm{ml}$ of the fasting venous blood was taken and sent to the laboratory to check the blood routine and blood biochemistry; automatic blood cell analyzer and blood biochemical analyzer were used for detection. The serum inflammatory factor IL-6 was detected by enzyme-linked immunosorbent assay (ELISA). The operation was carried out in strict accordance with the manual. The kit was purchased from eBioscience company (EPX650-16500-901).

\section{Statistical Analysis}

SPSS 19.0 was used. The counting data of normally distributed measurements was expressed by $\bar{x} \pm s$, $t$-test was conducted, and the measurement data in percentage were tested by $\chi^{2} / t . P<0.05$ was considered statistically significant.

\section{RESULTS}

\section{Comparison of Clinical Characteristics}

The general information of the 24 patients developing from moderate to severe condition on admission included: the median age, which was 56 years (21-83 years); 15 males $(62.50 \%)$ and nine females (37.50\%); and 13 patients $(54.17 \%)$ with one or no common underlying diseases, and 11 patients (45.83\%) with more than two kinds of common underlying diseases, such as hypertension, coronary heart disease, diabetes, etc. The 41 moderate patients were 30-78 years old, and the median age was 53 years old; there were 20 male patients $(48.78 \%)$, and 21 female patients $(51.22 \%) ; 36$ patients $(87.80 \%)$ had one or no common underlying diseases, and five patients (12.20\%) had more than two kinds of common underlying diseases. Among the 24 confirmed patients, symptoms and signs included: 21 patients $(87.50 \%)$ with fever, eight patients $(33.33 \%)$ with cough and sputum, three patients $(12.50 \%)$ with chest tightness and dyspnea, and no patients $(0 \%)$ with other symptoms. The main physical signs included increased respiratory frequency ( $\geq 24$ times $/ \mathrm{min}$ ) in eight patients (33.33\%). Among the 41 confirmed cases, 41 patients (100\%) had fever, 12 patients (29.27\%) had cough and expectoration, one patient $(2.44 \%)$ had chest distress and dyspnea, and one patient (2.44\%) had other signs. The main signs included increased respiratory rate $(\geq 24$ times/min) in five patients $(12.20 \%)$. By comparison, there were significant differences in combined common underlying diseases and respiratory frequency between the moderate group and the severe group ( $t$-values were $13.32,6.17$, respectively, $P<0.05$ ), while there were no significant differences in gender, age, or clinical symptoms between the two groups $(P>0.05)$ (Table 1$)$.

\section{Comparison of Blood Test Results}

The comparison of hematological indexes on the second day after admission of the two groups of patients showed that the 


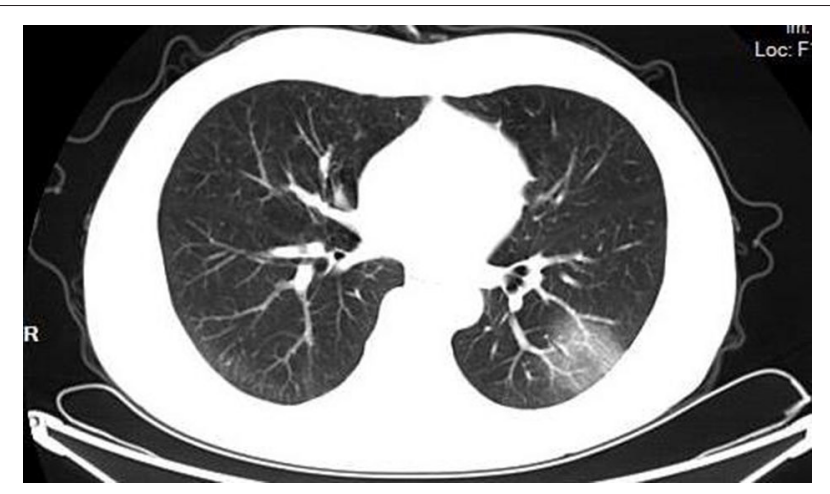

FIGURE 1 | Single ground-glass opacity.

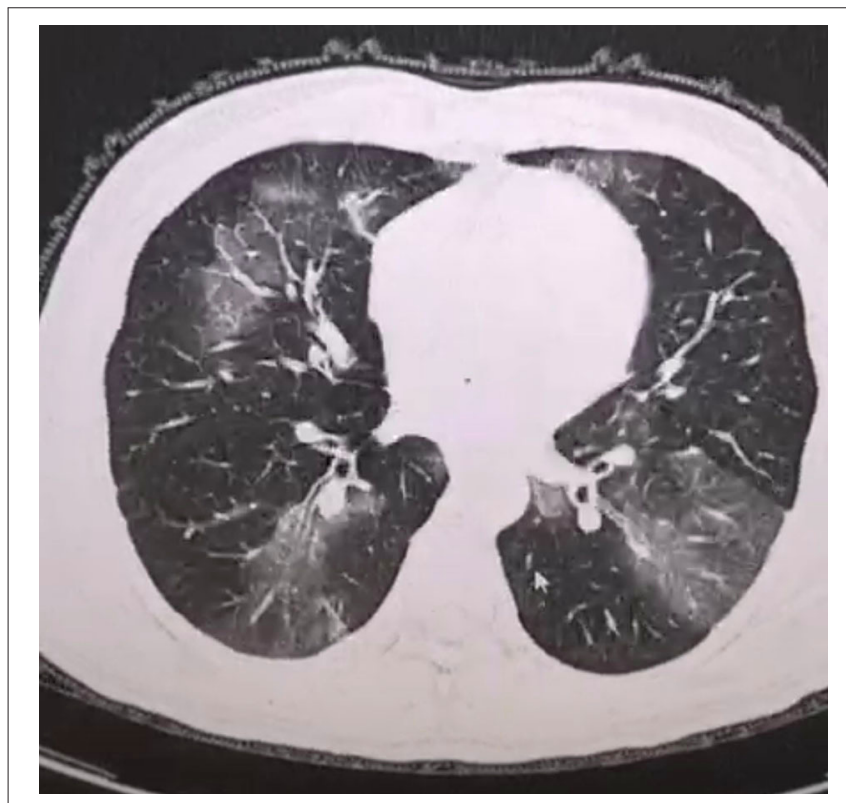

FIGURE 2 | Multiple external subpleural ground-glass opacity.

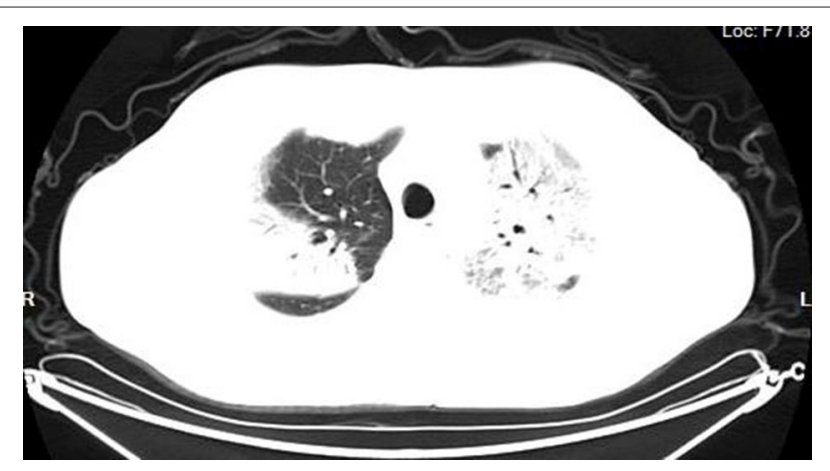

FIGURE 3 | Ground-glass opacity, patchy shadow, and consolidation shadow in both lungs.

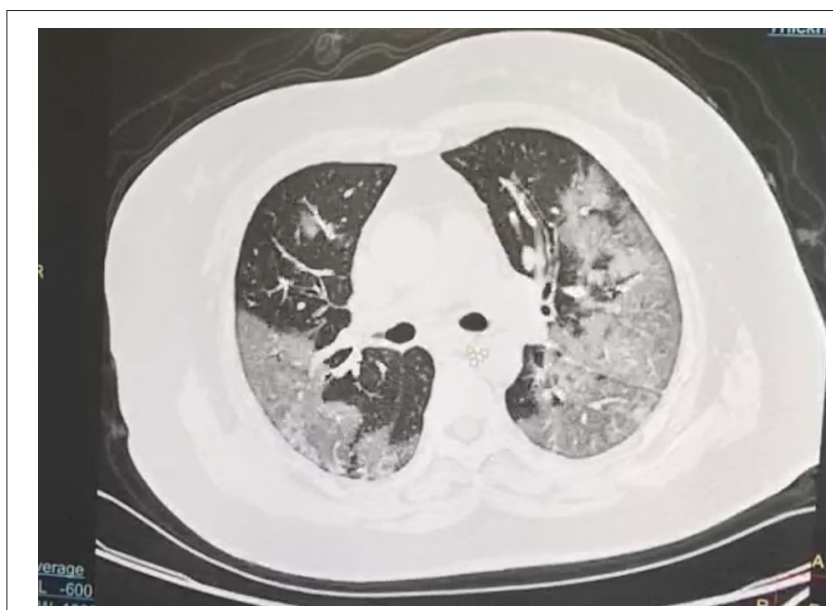

FIGURE 4 | Diffuse ground-glass opacity in both lungs accompanied by air bronchogram.

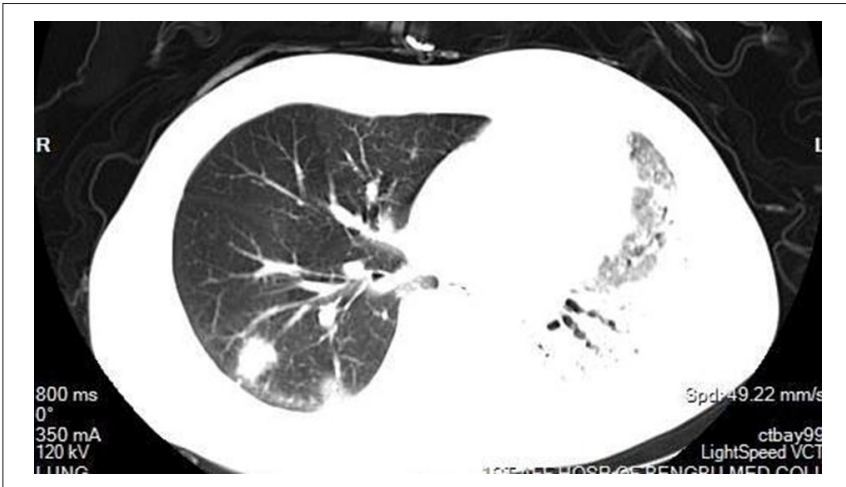

FIGURE 5 | Large area consolidation of both lungs with pulmonary interstitial changes.

lymphocyte count and plasma albumin in the moderate-tosevere group were significantly lower than that in the moderate group ( $t$-values were $4.16,4.11$, respectively, $P<0.05$ ). The levels of blood glucose and urea in the moderate-to-severe group were significantly higher than the moderate group ( $t$-values were $3.27,4.19$, respectively, $P<0.05$ ). However, there was no significant difference in terms of white blood cell count (WBC), platelet count (PLT), or glutamic-pyruvic transaminase (GPT) $(P>0.05)$ (Table 2).

\section{Comparison of Inflammatory Indicators}

The levels of IL- 6 and CRP of the moderate-to-severe group were significantly higher than those of the moderate group ( $t$-values were $2.84,4.88$, respectively, $P<0.05$ ) (Table 3 ).

\section{Comparison of Imaging Manifestation}

According to the CT imaging manifestation of 65 COVID-19 patients, the typical imaging signs were (Figures 1-5): (1) single ground-glass opacity (GGO); (2) multiple external subpleural ground-glass opacity; (3) concurrence of ground-glass opacity, 
TABLE 4 | Comparison of imaging manifestation between the two groups.

\begin{tabular}{|c|c|c|c|c|}
\hline $\begin{array}{l}\text { Imaging } \\
\text { manifestation }\end{array}$ & $\begin{array}{c}\text { Moderate-to- } \\
\text { severe Group (\%) }\end{array}$ & $\begin{array}{l}\text { Moderate } \\
\text { Group (\%) }\end{array}$ & $t$ & $P$-value \\
\hline Single ground-glass opacity & $1(4.17 \%)$ & $8(19.51 \%)$ & 10.92 & $<0.05$ \\
\hline $\begin{array}{l}\text { Multiple external subpleural } \\
\text { Ground-glass opacity }\end{array}$ & $4(16.67 \%)$ & $17(41.46 \%)$ & & \\
\hline $\begin{array}{l}\text { Ground-glass opacity, patchy } \\
\text { shadow and consolidation } \\
\text { shadow in both lungs }\end{array}$ & $11(45.83 \%)$ & $10(24.39 \%)$ & & \\
\hline $\begin{array}{l}\text { Diffuse ground-glass opacity in } \\
\text { both lungs accompanied by air } \\
\text { bronchogram }\end{array}$ & $7(29.16 \%)$ & 6 (14.64\%) & & \\
\hline $\begin{array}{l}\text { Large area consolidation of both } \\
\text { lungs with pulmonary interstitial } \\
\text { changes }\end{array}$ & $1(4.17 \%)$ & 0 & & \\
\hline
\end{tabular}

TABLE 5 | Comparison of antiviral treatment between the two groups.

\begin{tabular}{lcccc}
\hline $\begin{array}{l}\text { Antiviral } \\
\text { treatment }\end{array}$ & $\begin{array}{l}\text { Moderate-to- } \\
\text { severe Group }\end{array}$ & $\begin{array}{c}\text { Moderate } \\
\text { Group }\end{array}$ & $\chi^{2}$ & $P$-value \\
\hline $\begin{array}{l}\text { Combination of 2 } \\
\text { antiviral treatment }\end{array}$ & 20 & 35 & 0.05 & $>0.05$ \\
$\begin{array}{l}\text { Combination of 3 } \\
\text { antiviral treatment }\end{array}$ & 4 & 6 & & \\
\hline
\end{tabular}

patchy shadow, and consolidation shadow in both lungs; (4) diffuse ground-glass opacity in both lungs accompanied by air bronchogram; and (5) large area consolidation of both lungs with pulmonary interstitial changes. Comparisons of the imaging manifestation between the two groups showed a statistically significant difference $(t=10.92, P<0.05)$. In terms of the proportion of the latter three typical signs, the moderate-tosevere group was higher than the moderate group (Table 4).

\section{Comparison of Antiviral Treatment}

For clinical antiviral treatment of COVID-19, according to the current scheme, it is recommended to use abidol, klidge, interferon, chloroquine, ribavirin, etc. Two or three used in conjunction are recommended. The dosage, method, and course of treatment are in accordance with the national covid-19 treatment program. This study shows no statistically significant difference in the combination of two antiviral drugs or the combination of three antiviral drugs between the two groups $\left(\chi^{2}=0.05, P>0.05\right)$ (Table 5).

\section{DISCUSSION}

It can be suggested that some of the moderate patients can develop to the severe type, or even to the critical type, within a very short period of time from the clinical work, which makes the improvement of the remedy rate of clinical treatment more difficult. The detection of these patients from the early stage will be worthwhile to the improvement of diagnosis and treatment. This study analyzed the clinical data of 24 COVID19 patients admitted to our hospital developing from moderate to severe condition, and compared this with the clinical data of 41 moderate patients in the same period; the results were consistent with the results of Guo et al. (2019). The most common underlying diseases are hypertension, diabetes, and coronary heart disease. This may be because the majority of patients are the elderly with a compromised immunity, so we should pay extra attention to elderly patients. However, further analysis of gender, age, and clinical symptoms revealed no significant correlation with the development from moderate to severe condition $(P>0.05)$, which might be attributed to the small number of cases. (2) Compared with the hematological indexes of the two groups after admission, the lymphocyte count and plasma albumin levels in the moderate-to-severe group were significantly lower than those in the moderate group ( $t$-values were 4.16, 4.11 , respectively, $P<0.05$ ). The decrease of lymphocyte count indicates the possibility of immune impairment, and the decrease of albumin may contribute to the hepatic albumin synthesis disorder caused by the direct damage of the virus to hepatocytes. Some researchers (Guo et al., 2019) proposed to use lymphocyte count $<0.8 \times 10^{9} / \mathrm{L}$ as one of the indicators to predict the death risk model of viral pneumonia. The moderate-to-severe group was significantly higher than the moderate group in blood glucose and urea ( $t$-values were $3.27,4.19$, respectively, $P<$ 0.05 ), these patients with elevated blood glucose and urea are more likely to develop to severe type. The increase of blood glucose may be connected with the severity of patients or the existence of complicated diabetes, while the increase of BUN may be related to the severe inflammatory response and the hypermetabolism caused by fever in severe patients. However, there was no significant difference in contrast with WBC, PLT, and GBT $(P>0.05)$. It is inferred that moderate patients with a low lymphocyte count and low albumin on admission are more likely to develop to severe condition, which is consistent with the results of most clinical studies (Chen Y. et al., 2020), thus more efforts should be given to these cases. With great individual diversities, we also found that patients had different immune responses to the virus, leading to vast varieties in clinical symptoms, disease progression, and response to therapeutic drugs (Castrucci, 2018). Therefore, for the clinical progression of COVID-19, we should also consider the differences in individual inflammatory responses and search for some objective indicators to help accurately predict the clinical progression and cover the deficiency.

It is well-known that the immune function can enable the body to acquire the defense ability required to resist external infection and eliminate foreign microorganisms, thereby inhibiting the infection and restoring health. But everything has two sides. When the virus invades the body, if the immune system is overactivated or out of control, it will produce an extreme immune response, and release large amounts of cytokines, which in turn attack the host. This phenomenon is called "inflammatory storm." Numerous evidences have shown that cytokines and chemokines are significantly elevated in patients with severe infection and are considered to reflect the severity of the disease (La Gruta et al., 2007). Studies have 
shown that the expression levels of serum IL-2R, IL-6, and other cytokines in patients with COVID-19 dramatically increased on average, particularly in the critical patients. Therefore, some scholars pointed out that peripheral blood IL- 6 could be applied as a key factor to independently predict the progression of COVID-19. It can be speculated on the basis of that, as a blocking target, IL-6 might have potential clinical value in inhibiting the inflammatory response. Tocilizumab, namely human anti-human interleukin- 6 receptor monoclonal antibody, suppresses the activity of IL- 6 in peripheral blood to block or reduce the inflammatory response (Yang et al., 2020). With the detection of serum CRP and IL- 6 in patients, we found that the levels of IL- 6 and CRP in the moderate-to-severe group were significantly higher than that in the moderate group ( $t$-values were $2.84,4.88$, respectively, $P<0.05$ ), indicating the possibility of immunocompromise. The moderate patients with elevated CRP and IL-6 are more likely to develop into severe condition.

In order to understand the status of lung lesions in COVID19 patients, we recommend chest HRCT to avoid misdiagnosis and missed diagnosis. Clinical studies have demonstrated that COVID-19 has characteristic manifestations in chest CT. According to the CT imaging manifestations of 65 COVID19 patients, the comparison of the imaging manifestations between the two groups of patients displayed that the latter three manifestations in the moderate-to-severe group were significantly higher than those in the moderate group $(t=$ 10.92, $P<0.05)$. It is necessary to note that COVID-19 patients rarely present with pleural effusion or lymphadenopathy (Medical Expert Group of Tongji Hospital Affiliated to Tongji Medical College of Huazhong University of Science Technology, 2020).

For antiviral treatment, the treatment scheme in "the Diagnosis and Treatment Scheme of the Pneumonia Caused by the Novel Coronavirus" established by the National Health Commission of the People's Republic of China has been constantly adjusted. $\alpha$ - interferon, lopinavir/ritonavir, abidor tablets, ribavirin, and chloroquine phosphate, can be trialed. With the ever-changing treatment courses, the joint application of three or more antiviral drugs is not recommended. For the vast majority of the studied cases, we adopted two antiviral drugs. For a small number of young patients, we tried three antiviral drugs with the consent of patients, which had no apparent effect on preventing the moderate patients from developing into severe

\section{REFERENCES}

Castrucci, M. R. (2018). Factors affecting immune responses to the influenza vaccine. Hum. Vaccines Immunother. 14, 637-646. doi: 10.1080/21645515.2017.1338547

Chan, J. F., Yuan, S., Kok, K. H., To, K. K., Chu, H., Yang, J., et al. (2020). A familial cluster of pneumonia associated with the 2019 novel coronavirus indicating person-to-person transmission: a study of a family cluster. Lancet 395, 514-523. doi: 10.1016/S0140-6736(20) 30154-9

Chen, L., Liu, H. G., Liu, W., Liu, K., Shang, J., Deng, Y., et al. (2020). Analysis of clinical features of 29 patients with 2019 novel coronavirus pneumonia. Chin. J. condition, and the difference between the two groups was not statistically significant $(P>0.05)$. Meanwhile, the time for the virus to turn negative was not shortened, and a proportion of patients even had adverse reactions. So, we do not recommend the use of more than two antiviral drugs, the exact efficacy of which needs further clinical observation.

In our study, the majority of the 24 moderate-to-severe patients developed into moderate condition after active treatment, one patient developed into critical condition, and all these patients were cured and discharged eventually. In conclusion, the risk factors for COVID-19 patients to develop from moderate to severe condition consists of: complicated common underlying diseases, respiratory frequency, lymphocyte count, blood glucose, albumin, urea, inflammatory factor (CRP, IL-6), and imaging manifestations. It is worth noting in clinical work that early detection and treatment is crucial to raise the cure rate and reduce the mortality. However, due to limited number of cases in this study, it may be necessary to conduct a meta-analysis of the relevant parts in further research to make the results more convincing.

\section{DATA AVAILABILITY STATEMENT}

The datasets presented in this study can be found in online repositories. The names of the repository/repositories and accession number(s) can be found in the article/ supplementary material.

\section{ETHICS STATEMENT}

The studies involving human participants were reviewed and approved by the First Affiliated Hospital of Bengbu Medical College (2020ky010).

\section{AUTHOR CONTRIBUTIONS}

DL, YY, CL, and YZ conceived and designed the study. DL, JH, and $\mathrm{YZ}$ contributed to the literature search. DL, JL, and YZ contributed to data collection. DL, JH, and YY contributed to data analysis. DL and YY contributed to data interpretation. DL, $\mathrm{CL}$, and JH contributed to the figures. YY and DL contributed to writing of the report. All authors contributed to the article and approved the submitted version.
Tuberc. Respir. Dis. doi: 10.3760/cma.j.issn.1001-0939.2020.0005. [Epub ahead of print].

Chen, Y., Liu, Q., and Guo, D. (2020). Emerging coronaviruses: genome structure, replication, and pathogenesis. J. Med. Virol. 92, 418-423. doi: 10.1002/jmv.25681

Guo, L., Wei, D., Zhang, X., Wu, Y., Li, Q., Zhou, M., et al. (2019). Clinical features predicting mortality risk in patients with viral pneumonia: the MuLBSTA score. Front. Microbiol. 10:2752. doi: 10.3389/fmicb.2019. 02752

Huang, C., Wang, Y., Li, X., and Ren, L. (2020). Clinical features of patients infected with 2019 novel coronavirus in Wuhan, China. Lancet 395, 497-506. doi: 10.1016/S0140-6736(20)30183-5 
La Gruta, N. L., Kedzierska, K., Stambas, J., and Doherty, P. C. (2007). A question of self-preservation: immunopathology in influenza virus infection. Immunol. Cell Biol. 85, 85-92. doi: 10.1038/sj.icb.7100026

Medical Expert Group of Tongji Hospital Affiliated to Tongji Medical College of Huazhong University of Science and Technology (2020). Quick Guide to Novel Coronavirus Infection in Pneumonia, 3rd Edn (EB/OL). Available online at: https://www.tjh.com.cn/html/2020/0128/28713.shtml\#title (accessed January 28, 2020).

Novel coronavirus pneumonia diagnosis and treatment plan of People's Republic of China national health and Health Committee (trial version sixth) [EB/OL]. Available online at: http://www.nhc.gov.cn/yzygj/s7653p/202002/8334a 8326dd94d329df351d7da8aefc2/files/b218cfeb1bc54639af227f922bf6b817.pdf

Ren, L. L., Wang, Y. M., Wu, Z. Q., Xiang, Z. C., Guo, L., Xu, T., et al. (2020). Identification of a novel coronavirus causing severe pneumonia in human: a descriptive study. Chin. Med. J. 133, 1015-1024. doi: 10.1097/CM9.0000000000000722

Wang, D., Hu, B., Hu, C., Zhu, F., Liu, X., Zhang, J., et al. (2020). Clinical characteristics of 138 hospitalized patients with 2019 novel coronavirus-infected pneumonia in Wuhan, China. JAMA 323, 1061-1069. doi: 10.1001/jama.2020.1585

Yang, P. H., Ding, Y. B., Xu, Z., Pu, R., Li, P., Yan, J., et al. (2020). Epidemiological and clinical features of COVID-19 patients with and without pneumonia in Beijing, China. Medrxiv [preprint]. doi: 10.1101/2020.02.28.20 028068

Conflict of Interest: The authors declare that the research was conducted in the absence of any commercial or financial relationships that could be construed as a potential conflict of interest.

Copyright (c) $2020 \mathrm{Li}, \mathrm{Liu}, \mathrm{Liu}, \mathrm{Hu}$, Yang and Zhou. This is an open-access article distributed under the terms of the Creative Commons Attribution License (CC BY). The use, distribution or reproduction in other forums is permitted, provided the original author(s) and the copyright owner(s) are credited and that the original publication in this journal is cited, in accordance with accepted academic practice. No use, distribution or reproduction is permitted which does not comply with these terms. 